\title{
CULTURAL HERITAGE: AN EXAMPLE OF GRAPHICAL DOCUMENTATION WITH AUTOMATED PHOTOGRAMMETRIC SYSTEMS
}

\author{
M. G. Giuliano ${ }^{a}$ \\ ${ }^{a}$ Seconda Università degli Studi di Napoli, Italy (giuliano.maria.grazia@gmail.com)
}

Commission V, WG V/2

KEY WORDS: 3D modeling, Cultural Heritage, Image Based Modeling, Photogrammetric, close-range, 3D modeling.

\begin{abstract}
:
In the field of Cultural Heritage, the use of automated photogrammetric systems, based on Structure from Motion techniques (SfM), is widely used, in particular for the study and for the documentation of the ancient ruins.

This work has been carried out during the PhD cycle that was produced the 'Carta Archeologica del territorio intorno al monte Massico'. The study suggests the archeological documentation of the mausoleum 'Torre del Ballerino' placed in the south-west area of Falciano del Massico, along the Via Appia. The graphic documentation has been achieved by using photogrammetric system (Image Based Modeling) and by the classical survey with total station, Nikon Nivo C.

The data acquisition was carried out through digital camera Canon EOS 5D Mark II with Canon EF 17-40mm f/4L USM @ 20mm with images snapped in RAW and corrected in Adobe Lightroom. During the data processing, the camera calibration and orientation was carried out by the software Agisoft Photoscans and the final result has allowed to achieve a scaled 3D model of the monument, imported in software MeshLab for the different view. Three orthophotos in jpg format were extracted by the model, and then were imported in AutoCAD obtaining façade's surveys.
\end{abstract}

\section{INTRODUCTION}

The development of low-cost automated photogrammetric systems is widely used in the field of Cultural Heritage, in particular it's applied for the study and for the documentation of the ancient ruins.

In the absence of technologies of Range Based Modeling (RBM), they allow more accurate but also more expensive measurements, the Image Based Modeling (IBM) technique has been selected as the better choice (Remondino and Menna 2008; Lo Brutto and Spera 2011).

Software based on IBM is able to digitalize documentation of little objects and also to correctly do surveys of monuments and archeological digs in a short time, with regular geometric shapes and low-budget projects (Barazzetti, L., Remondino, F., Scaioni, M., 2010). It seems to be very useful in circumstances of emergency. This technique is called Structure from Motion (SfM) and consists in the automatic camera calibration and orientation with algorithms derived from Computer Vision (CV).

Photogrammetric and SfM methods strongly depend on a correct strategy of shooting and on good images' quality (De Luca 2001), which both are necessary for the data acquisition and for the metric surveys.

The contact points in the close-range photogrammetric packages are selected with featuring-based-matching and bundle adjustment algorithms.

The result consists in the reconstruction of surfaces and threedimensional models which can be shared by researchers, generating a large contribution to the search in this field.

The work, presented in this article, suggests the archeological documentation of a roman mausoleum, well-preserved in the area of Falciano del Massico (CE), by the use of classical survey, in addition to a metric 3D model with IBM technique. This method allowed adding to the archeological documentation the inscription preserved in the bell tower of Carinola and probably connected to the mausoleum.
The study has been carried out during the $\mathrm{PhD}$ cycle in Metodologie Conoscitive per la Conservazione $e$ la Valorizzazione dei Beni Culturali, that was produced as the 'Carta archeologica del territorio intorno al Monte Massico', and this area corresponds to a small part of the ancient ager Falernus.

The graphic documentation has been achieved by using the total station, Nikon Nivo C, as classical survey while the 3D model has been obtained by using the software Agisoft Photoscan.

The comparison between the two techniques has permitted to take account of IBM system's quality and precision oppositely to the classical surveys.

\section{THE CASE STUDY}

The mausoleum in the district of 'Torre del Ballerino', along the Via Appia and placed in the south-west area of Falciano del Massico, is a quadrangular structure $(8.27 \times 6.35 \mathrm{~m})$ built in opus caementicium (figure 1). The monument consists in a plinth formed by squared limestone blocks (about $50 \times 50 \mathrm{~cm}$ ) put in order on two-row, sticking out for about $50 \mathrm{~cm}$, barely preserved along the north and the west side.

Above the southern side, the monument is covered by a shrub that doesn't allow valuing the ancient ruin's conservation.

On the plinth there is the quadrangular structure elevated for 7.30 meters, built with a pour of flake limestone tied with mortar into formworks, upholstered by stone slabs; on the surface there are the subfloors that articulate the various phase of the construction. The gateway of the burial chamber, as usual, is on the opposite side of the Via Appia and it consists by limestone blocks that gauge a doorway width of about $80 \mathrm{~cm}$ (for the baseline) and $67 \mathrm{~cm}$ (on the top) with a lateral set of piers with a height of 1.60 meters while the preserved blocks on the base supporting the piers measure respectively $42 \times 56 \mathrm{~cm}$ 
and $47 \mathrm{x} 54 \mathrm{~cm}$; lastly, the architrave's dimensions are $0.36 \times 1.03$ meters.

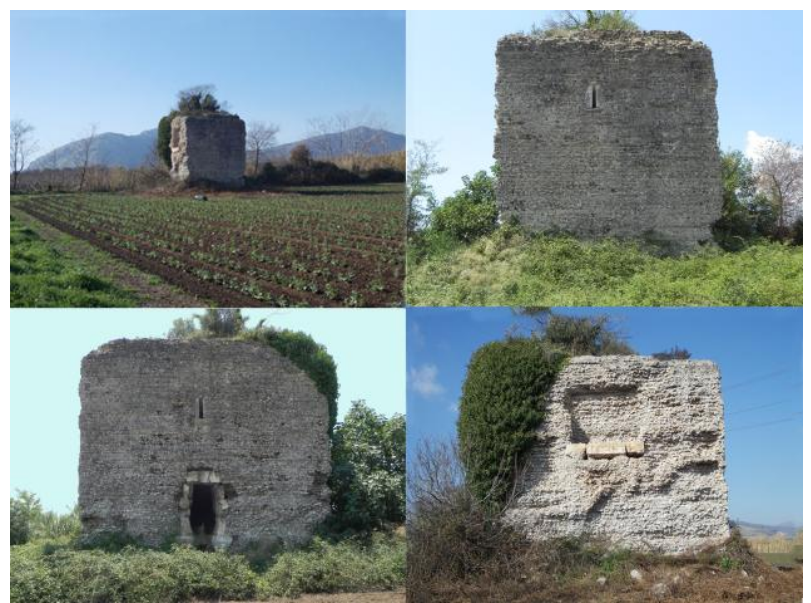

Figure 1. Ruins of the mausoleum 'Torre del Ballerino'.

Currently, the burial chamber is inaccessible and it seems to have a square shape ( 3.25 meter each side), with walls built in opus quadratum bearing splayed openings, defined outside by rectangular slabs (Pagano 1991-1992). The airshaft windows are visible on the western $(68 \times 11 \mathrm{~cm})$ and the northern $(70 \times 14 \mathrm{~cm})$ side, while it lacks that on the eastern side. Above the entrance's baseline there is a cut made by clandestine excavations that brought to the removal of many limestone blocks, which maybe belonged to the stairway access.

The mausoleum's side above the Via Appia preserve a quadrangular niche measuring 2 meter for the height and 2.40 meter for the width, with a large limestone block as baseline, divided in three small parts (2.68x0.37 meters). The niche was used to hold the mausoleum's decorations and the memorial's inscription, related to the deceased. This inscription has been identified with the CIL X 4727, currently preserved and reused in the bell tower of Carinola, and it seems to have the same sizes of the niche (Crimaco 1993).

The development of this type of burials is exclusively linked to the social reason: the mausoleum becomes self-celebration, instrument of communication between the owner of the tomb and the community, thus assuming a clear individualistic connotation (Von Hesberg 2008).

\section{SURVEY PROCEDURES}

The first step concerned the data and the image acquisition for the 3D model and the measurement of some photogrammetric control points through total station.

The second step was the data processing: the images were corrected with the software Adobe Lightroom while the cameras calibration and orientation were carried out with Agisoft Photoscan, obtaining the three-dimensional model and then the orthophotos of the visible surfaces.

Then the ortophotos were imported in AutoCAD to compare them with the control's points obtained through total station: the comparison between two systems has been very important to value the quality and the accuracy of the $3 \mathrm{D}$ model, in addition to the surveys obtained by orthophoto.

\subsection{Photogrammetric data acquisition}

The work is carried out through digital reflex camera Canon EOS 5D Mark II sensor size 36x24 mm (type CMOS, full frame) and pixel size $6.4 \mu \mathrm{m}$, lens Canon EF $17-40 \mathrm{~mm}$ f/4L USM, with a fixed focal length lenses of $20 \mathrm{~mm}$.

In the specific case, a close-range block of 37 images has been used while the shooting has been carried out with a distance of 7 meters to the monument and about 1 meter between an image and the other. The GSD (Ground Simple Distance) was equal to about $2.24 \mathrm{~mm}$.

Two levels of photographic shots were performed with a first close-range block in the low part of the monument and a second block in the high part, covering all the occlusions generated by dominant plans with axes convergent and parallel shots near the angle and then the visible side of the mausoleum; both shots were later supplemented during the alignment of the cameras. Regarding the digital documentation of small artifacts, it has been decided to perform another photogrammetric shooting, in particular the commemorative's inscription preserved in the tower bell of Carinola, connected with the mausoleum. In this case, have been used 17 shots carried out through a digital camera, Nikon Coolpix L23. The close-range images have been performed with three distance's levels from the artifact (range of reference: 0.60 meters; 3 meters; 5 meters). The first block of 6 images is carried out with a general view while the second, about 11 images, with a detailed view in particular for some carved letters.

\subsubsection{Photogrammetric data processing}

The photogrammetric data processing was carried out with the software SfM, Agisoft Photoscan. The software allows image's close-range matching, with the identification of homologous points supporting the automatic camera's calibration and orientation (internal and external).

Images, snapped in RAW, have been developed and corrected in Adobe Lightroom and exported in JPG format.

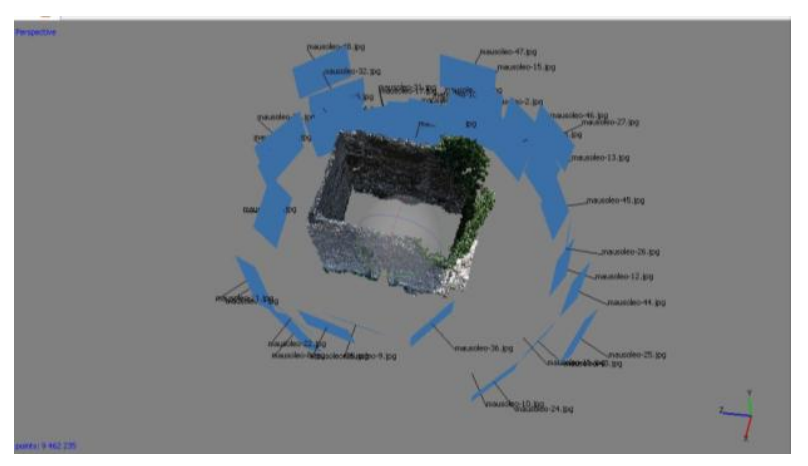

Figure 2. Mausoleum: the camera calibration and orientation.

In the data processing step, shots have been developed on the same chunk, obtaining a dense cloud of $2 \mathrm{mln}$ points and a high resolution smooth geometry. The final result has allowed to obtain a 3D model measured through reference points or markers, chosen on the surface, and then scaled with known distances (Figure 2). Finally, a texture-mapping is performed obtaining photo-realistic visualization of three-dimensional model (fig. 3). 


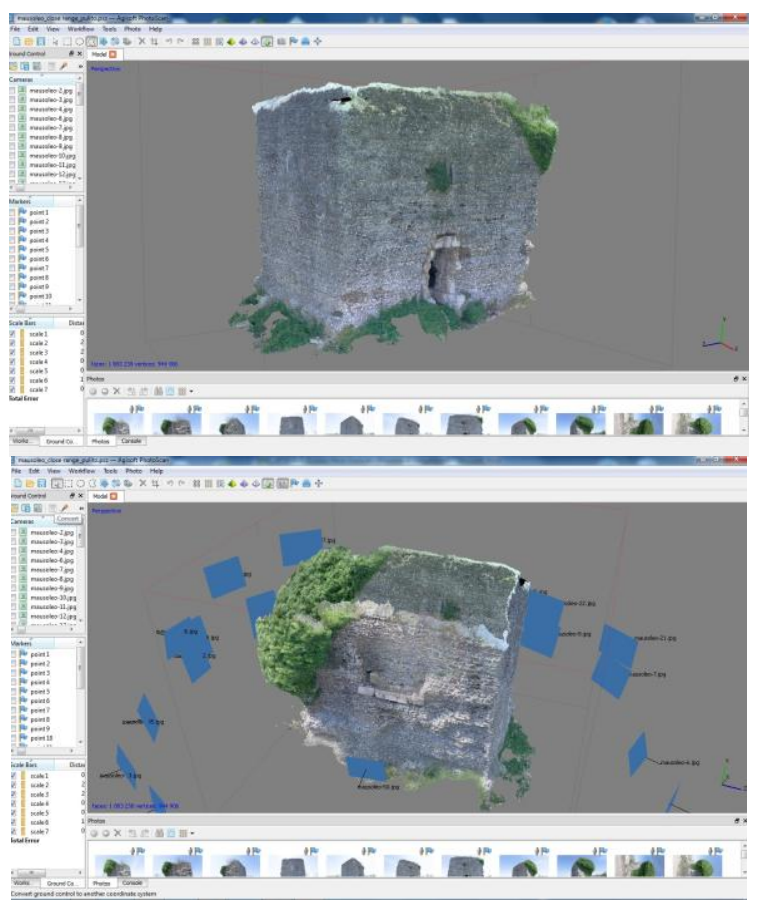

Figure 3. Photogrammetric data processing by Agisoft Photoscan.

Three orthophotos in jpg format were extracted by the model, and then were imported in AutoCAD obtaining façade's surveys (Figure 4), while a $o b j$ format was also extracted displaying the model in Meshlab.

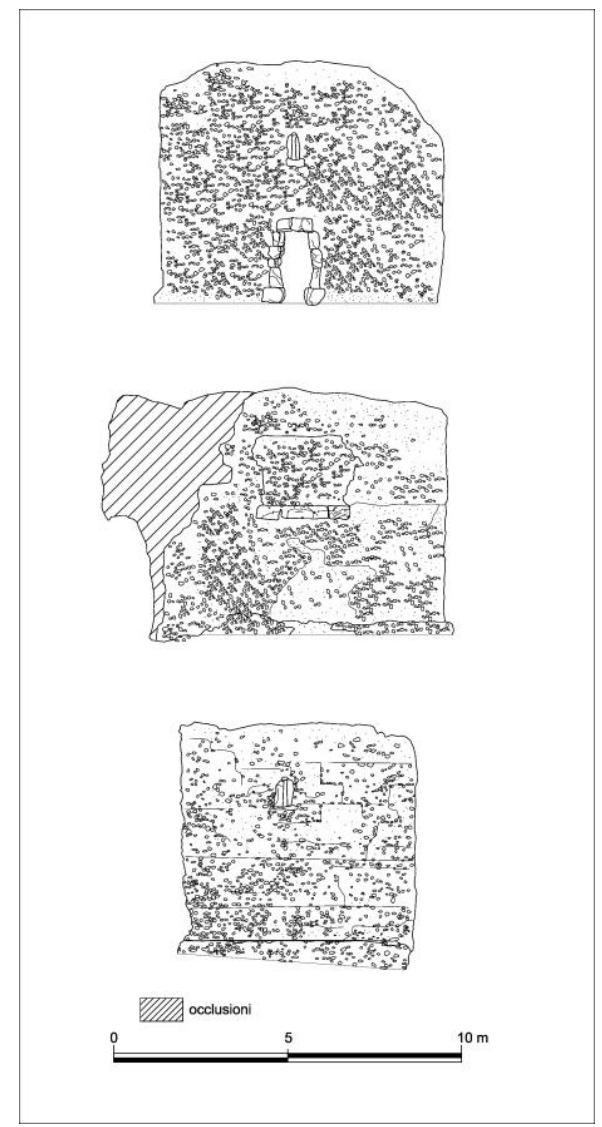

Figure 4. Mausoleum' surveys by orthophotos.
Regarding the inscription's model, the procedure has been the same: during data processing, a block of 17 images was aligned obtaining a surface's 3D, used especially for the archeological and digital documentation (Figure 5). This technique, in fact, allows standing out the carved letter for the epigraphic study while the 3D model could also be shared by researchers for this purpose; in this case, a view in Meshlab allows a surface's detailed analysis.

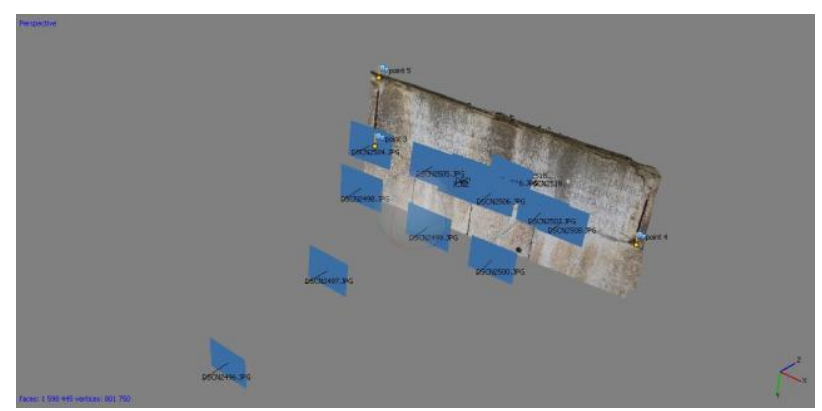

Figure 5. Inscription: elaboration in Agisoft Photoscan.

\subsubsection{Meshlab data post-processing}

The mausoleum's 3D model obtained in Agisoft Photoscan was exported in obj format and displayed in Meshlab.

The display and lights' styles have allowed to highlight interesting traces for a surface's reading of the monument with interesting elements that appear poorly visible on the photogrammetric image (Figure 6).
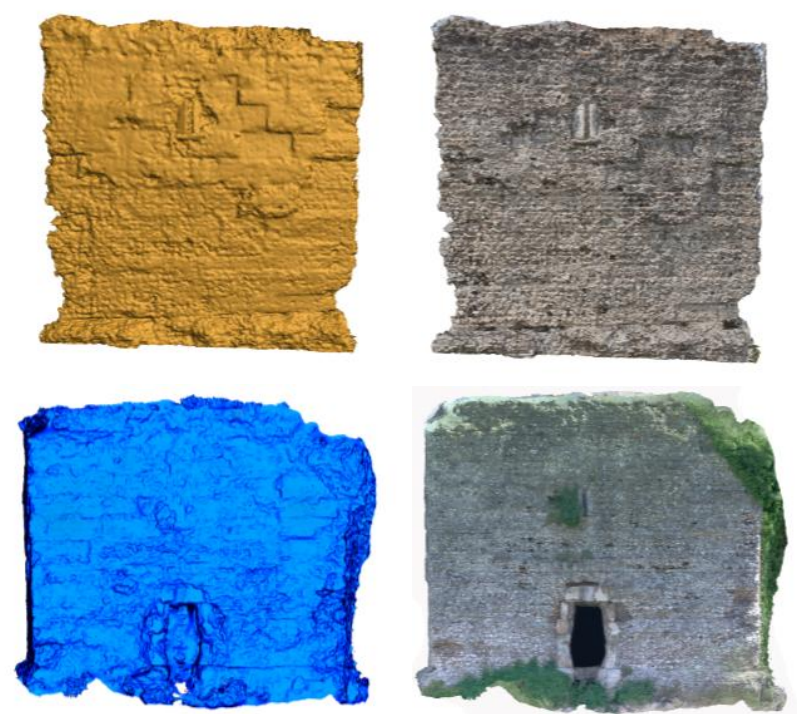

Figure 6. The mausoleum's model imported in Meshlab.

The detailed analysis of the mesh allowed, in fact, to observe slight 'impressions' of a square shape with dimensions of 0.80 to $1.08 \times 0.50$ meters, visible along the northern and western parts of the mausoleum that would leave hypothesize the presence in ancient of an outer coating, consisting of limestone slabs in opus quadratum, probably held together by metal clamps (Carbonara and Messineo 1998; Stortoni 2008).

The same procedure was applied to the inscription's 3D model putting on display the carved letters (Figure 7). 


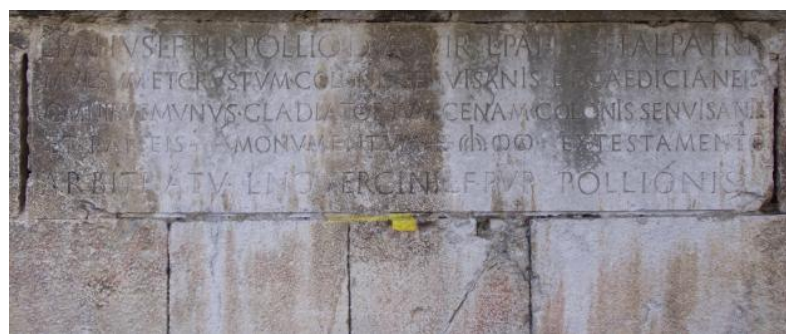

Figure 7. Orthophoto's inscription

\subsection{Total station data acquisition}

Some control points were acquired using total station, Nikon Nivo C, with four principal points of the station, three arranged at the corners of the monument and the last along the western façade. The measurements were made with a prism for the lowest points and reflectorless technology for large parties. The file in .dxf format was imported into AutoCAD for postprocessing data (Figure 8 ).

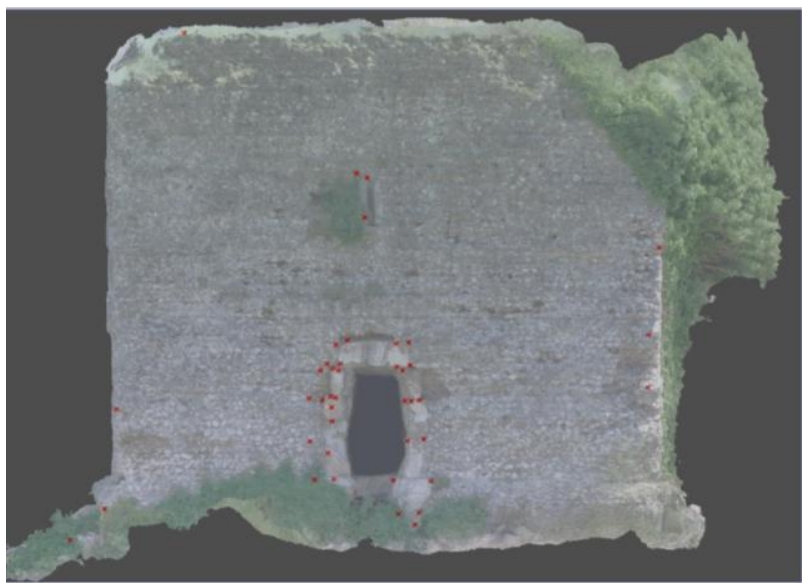

Figure 8 . The comparison between surveys of the total station and the IBM method.

\subsection{Volumetric 3D model}

The archeological surveys with the photogrammetric data obtained during the post-processing phase allow finally to realize a volumetric 3D model of the mausoleum by the software autoCAD (Figure 9) for the volume render and by the software 3DS Max for the different camera view (Figure 10).

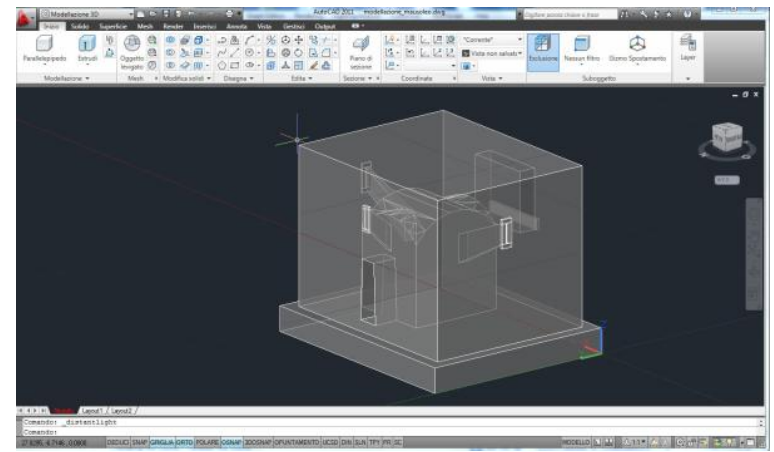

Figure 9. Volumetric 3D model with autoCAD
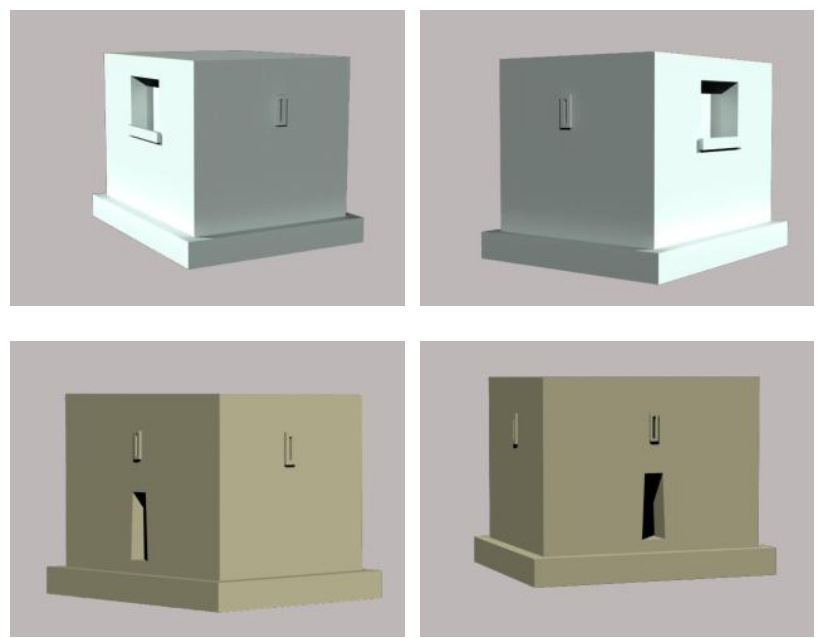

Figure 10. Different model's views by 3DS Max

\section{COMPARISON AND CONCLUSION}

The comparison between these two different techniques (the classical survey by using the total station and IBM method by Agisoft Photoscan) allows analyzing many aspects. The average deviation results with an error of 0.044 meter, due to the occlusion and to lack of oblique UAV images over the monument (Figure 11).

\begin{tabular}{|c|c|c|c|}
\hline \multicolumn{2}{|c|}{ Scale Bârs } & Distance $(\mathrm{m})$ & Error (m) \\
\hline V 目 & scale 1 & 0.335000 & -0.022529 \\
\hline$\nabla$ 目 & scale 2 & 2.050000 & -0.071662 \\
\hline D & scale 3 & 2.090000 & -0.076045 \\
\hline V 眘 & scale 4 & 0.340800 & -0.034861 \\
\hline V 夏 & scale 5 & 0.640000 & 0.024782 \\
\hline$\nabla$ 目 & scale 6 & 1.040000 & 0.020915 \\
\hline 目 目 & scale 7 & 0.870000 & 0.004207 \\
\hline \multicolumn{3}{|c|}{ Total Error } & 0.044256 \\
\hline
\end{tabular}

Figure 11. Average deviation in Agisoft Photoscan

It becomes necessary combining feature-based and area-based matching algorithms in order to obtain a detailed 3D reconstruction (Remondino and Menna 2008).

In addition, during photogrammetric data acquisition, codedtargets have not been used to optimize the camera calibration and image orientation phases, due to the difficulty of positioning reference's points not only in the low parts of the mausoleum but also in the high parts.

In photogrammetric data processing, the matching images could be improved with the targets, in fact, in this case the mausoleum's surface geometry has several repetitive elements (due to the architectural technique, built with a pour of flake limestone tied with mortar) that generate some outliers, so the contact's points recognizable by the software are few.

In this case, in terms of accuracy the traditional survey with interactive measurements seems to be the better choice, obtaining a detailed archeological documentation. Instead, the surface's analyses could be obtained by the 3D model and the different styles of view in Agisoft Photoscan and Meshlab. 
Finally, the IBM technique could give a great contribution to the digital documentation and conservation of archeological sites, monuments and objects, especially in circumstances of emergency, but also could be used to obtain façade's surveys, as in the case presented, through texture information.

The classical survey and SfM method can be used together with many advantages (time, costs, potentiality, quality, accuracy), however, the IBM technique needs a great attention especially during photogrammetric data acquisition; it should not be forgotten that the identification of appropriate measurements and modeling procedures are very important for the correct elaboration of the data (Barazzetti, L., Remondino, F., Scaioni, M., 2010).

\section{ACKNOWLEDGEMENT}

This study was development during the $\mathrm{PhD}$ cycle in Metodologie conoscitive per la Conservazione e la Valorizzazione dei Beni Culturali - Seconda Università degli Studi di Napoli; Tutor of research: Prof. Stefania Gigli Quilici. Total station data acquisition and photogrammetric data acquisition has been carried out in collaboration with $\mathrm{dr}$. Simone Gianolio.

\section{REFERENCES}

\section{References from Journals}

Remondino, F., El-Hakim, S., 2006. Image-based 3D modelling: a review. Photogrammetria, 21(115), pp. 269-291.

\section{References from Books}

Carbonara, A., Messineo, G., 1998. Via Appia III, da Cisterna a Minturno. Roma, p. 127.

Crimaco L., 1993. Prospettive di memoria, testimonianze archeologiche dalla città e dal territorio di Sinuessa. Gaeta, pp. 41-44.

De Luca, L., 2011. La fotomodellazione architettonica. Rilievo, modellazione, rappresentazione di edifici a partire da fotografie. Palermo, pp. 33-62.

Stortoni, E., 2008. Monumenti funerari di età romana nelle province di Macerata, Fermo e Ascoli Piceno I-II. Urbino, pp. 285 ss.

\section{References from Other Literature}

Alby, E., Elter, R., Ripoche, C., Quere, N., 2013. Close range photogrammetry applied to the documentation of an archeological site in Gaza Strip, Palestine. In: International Archives of the Photogrammetry, Remote Sensing and Spatial Information Sciences. Strasbourg, Volume XL, pp. 19-24.

Barazzetti, L., Remondino, F., Scaioni, M., 2010. Automation in 3D reconstruction: results on different kinds of close range blocks. In: The International Archives of the Photogrammetry,
Remote Sensing and Spatial Information Sciences, Commission V Symposium, Newcastle upon Tyne, UK, Vol. XXXVIII, Part 5, pp. 56-61.

Lo Brutto, M., Spera, M. G., 2011. Image-based and rangebades 3D modeling of archeological cultural heritage: the Telamon of the temple of Olympian Zeus in Agrigento (Italy). In: International Archives of the Photogrammetry, Remote Sensing and Spatial Information Sciences, Commission V Symposium, Trento, Vol. XXXVIII, Part 5, , pp. 515-522.

Hassani, F., Rafiee, M., 2013. An experience in cultural Heritage documentation in Iran using a low-cost technique. In: International Archives of the Photogrammetry, Remote Sensing and Spatial Information Sciences. Strasbourg, Volume XL-5, pp. 313-318.

Manferdini, A. M., Galassi, M., 2013. Assessments for 3D reconstructions of Cultural Heritage using digital technologies. In: International Archives of the Photogrammetry, Remote Sensing and Spatial Information Sciences. Trento, Volume XL, pp. 167-174.

Pagano M., 1991-1992. La via Appia fra Sinuessa e Capua alla luce di un nuovo miliario. In: Rendiconti dell'Accademia di Archeologia, Lettere e Belle Arti di Napoli. Napoli, Vol. LXIII, pp. 109-124.

Quilici, L., 1989. La via Appia, II, dalla pianura Pontina a Brindisi. In: Itinerari d'arte e di cultura. Via Appia. Roma, pp. 28 e 34.

Remondino, F., Menna, F., 2008. Image-Based surface measurement for close-range heritage documentation. In: The International Archives of the Photogrammetry, Remote Sensing and Spatial Information Sciences, Beijing, Vol. XXXVII, Part B5, pp. 199-206.

Schuhr, W., Lee, J. D., Kiel, St., 2013. 3D Photographs in Cultural Heritage. In: International Archives of the Photogrammetry, Remote Sensing and Spatial Information Sciences. Strasbourg,Volume XL-5, pp. 567-572.

Vianna Baptista, M. L., 2013. Documenting a complex modern Heritage building using multi image close range photogrammetry and 3D scanned point clouds. In: International Archives of the Photogrammetry, Remote Sensing and Spatial Information Sciences. Strasbourg, Volume XL-5, pp. 675-678.

Von Hesberg, H., 2008. Monumenta. Alcune riflessioni. In: Monumenta. I mausolei romani, tra commemorazione funebre e propaganda celebrativa, Monte Porzio Catone, pp. 13-22.

Wenzel, K., Abdel-Wahab, M., Cefalu, A., Fritsch, D., 2012. High-resolution surface reconstruction from imagery for close range cultural Heritage applications. In: International Archives of the Photogrammetry, Remote Sensing and Spatial Information Sciences. Melbourne, Volume XXXIX-B5, pp. 133-138. 